\title{
Conclusion
}

\author{
Martha Chen, Françoise Carré and Sally Roever
}

The Introduction to this volume summarises the recent rethinking on the informal economy by the chapter authors. This Conclusion presents the recommendations of the authors for future research and policy on the informal economy. Their recommendations build and expand upon the recent rethinking to keep pace with current and predicted changes to economies, to cities, to societies and to the environment which will reshape and challenge the livelihoods of informal workers going forward. As noted in the Introduction, these changes include structural shifts and the financialisation of economies; the expanded use of digital technologies, robotics and artificial intelligence; increased rural-urban and cross-border migration; and increased urbanisation and the resulting intensified competition for urban space and economic opportunities.

\section{Future research}

\section{Paradigm shift}

Regarding the overall approach to future research on the informal economy, the authors make four overarching sets of recommendations, which together call for a paradigm shift which privileges grounded theory building that is transdisciplinary in approach, features the perspectives of informal workers and pays attention to structural drivers of - and segmentation within - the informal economy. The first set of recommendations relates to the source of knowledge and theory. The authors emphasise that research and theory-building should be situated in realities and perspectives from the Global South where informal employment is predominant and where most informal workers live and work: more specifically, that future research should interrogate the ground realities of different groups of informal workers; that future theories (as well as policy and legal frameworks) should reflect these ground realities rather than the realities of (largely formal) employment in the Global North; and that future theories (and related policy or legal frameworks) should be built inductively, ideally reflecting the lived experiences and perspectives of informal workers.

As a notable example, the WIEGO (Women in Informal Employment: Globalizing and Organizing) Network is committed to co-producing knowledge with 
local organisations of informal workers and to featuring the voice and knowledge of informal workers in its research reports (Ogando and Harvey 2019). In most of its field research projects, as Marty Chen details in Chapter 6, WIEGO partners with local organisations of informal workers in all stages of the research process:

- to jointly select priority topics;

- to formulate testable hypotheses and specify appropriate questions;

- to identify and train local researchers;

- to identify and contact the sample population;

- to interpret the research findings;

- to draw out the policy lessons and messages.

The second set of recommendations relates to the type of research. The authors emphasise the need for cross-disciplinary research - ideally forging a transdisciplinary approach - to fully understand the dynamics of informal employment, including what drives it, the working conditions of different groups of informal workers and the links between informal employment, the state and capital. As Jan Breman puts it: "Interdisciplinarity is the alpha and omega of informality: the interconnectedness across the fields parcelled out of economics, political science, sociology, anthropology, law, social policy and public administration needs to be mapped." Also, many authors call for policy-relevant research, not just research aimed at theoretical debates or academic audiences.

The third set of recommendations relates to the unit of analysis for future research. The authors agree that aggregate measures of the size, composition and contribution of the informal economy are needed to attract the attention of researchers and policy-makers but that disaggregated data and research findings on different segments of the informal workforce are needed to understand informality and inform effective policy. Future policy-relevant research should, for instance, include interrogation of the working conditions of specific groups of informal workers and how different policies, laws and regulations impact them. Such an approach would help provide a corrective to existing literature that assumes away the different logics governing different groups of workers and the value chains in which they are embedded.

Fourth, the authors also call for research that bridges analysis at the macro, sectoral and micro levels to bring out the structural drivers of informality and the structural links between the informality of labour, capital and the state. This focus on structural drivers and links would help make visible the actors and logics that shape the possibilities for inclusive rights-based policy and legal frameworks and, thereby, for slowing or reversing the current trend towards extreme inequality. While the existing literature offers substantial insights into individual-level or supply-side constraints, it has far less to say about the structural dynamics within which informal enterprises and workers operate. This component of a future approach to research would help provide an important corrective to that imbalance and would help inform more nuanced and appropriate policy interventions. 


\section{Methods}

In terms of research methods, the authors recommend combining different research tools - statistical analysis, desk research and field research - recognising the limitations of each: that statistics often fail to capture dynamics and linkages; that existing literature is often context-specific and outdated; and that field research often does not produce generalisable findings.

The authors recommend using mixed methods in field research, both qualitative and quantitative. They also call for economic histories that explore the impact on informal employment of structural shifts over time in the wider economy and labour market.

In addition to statistical analysis favoured by economists and other policymakers and to truly understand informality in different contexts, the authors call for in-depth case studies as well as structural comparisons of such case studies. Jan Breman recommends a wide range of grounded case studies which trace the connection and interactions between informal workers and other actors or stakeholders and for "a cross-cutting analysis of existing case studies from a variety of analytical perspectives related to the world of informality". Caroline Skinner and Vanessa Watson also prioritise detailed case study work, especially in what are often regarded as "peripheral" informal areas in "ordinary" cities and towns, to generate "[h]ighly contextualised knowledge of the interests, power relations and actual daily practices underpinning inclusionary planning processes". The chapters on specific groups of informal workers in this volume demonstrate the analytical power of this in-depth approach.

\section{Themes}

The authors identify several broad themes as well as specific topics for future research.

One broad theme is prospective: the impact of current trends - migration, urbanisation, climate change, different patterns of economic growth, demographic change and the pressure to formalise - on informal employment in general and on specific groups of informal workers. A second is retrospective: the history of the informal economy in specific contexts and, more generally, the impact of structural shifts in the economy on the allocation of labour in different contexts. The third, for future statistical work and research, is to better understand and measure the productivity and economic contribution of the informal economy: informed by an analysis of how these are conceptualised and measured in mainstream economics, and official statistics, compared to the realities of informal employment and the perceptions of informal workers. Fourth, it is necessary to explore and analyse contexts where there have been positive and/or negative changes for the livelihoods of informal workers, including: who or what was driving the change, and why; and how was pressure applied. One concrete priority recommendation is to assess obstacles and setbacks to informal workers' efforts to organise and to negotiate 
with powerful agents (city agencies, contractors, developers) whose actions impact their livelihoods.

Another broad topic for future research is segmentation within the informal workforce, especially among the self-employed. The authors recommend several ways to consider segmentation within informal self-employment, including: old and new modes of production (e.g., artisanal and digital); different statuses of employment (employers, own-account operators, contributing family workers as well as disguised wage employees and dependent contractors); different products (traditional and modern, perishables and consumer durables) and markets (local, national and international); and contrasting strategies of the self-employed (e.g., multiplication versus accumulation).

Yet another is to map out and analyse the often-overlooked links between informal workers and the state (at all levels), on one hand, and corporate enterprises, the owners of capital and markets, on the other. Some authors recommend unpacking how these links are mediated, focusing on both the actors - the intermediaries (e.g., middlemen, the mafia) - and the vested interests and politics involved. As Barbara Harriss-White puts it, the boundary between informality and the state is not so much "blurry" as "political", a function of the exercise of power by the state and/or the owners of capital.

Finally, several authors called for theorising the use of public space for informal livelihoods, notably public space and public land in cities and forest, pastures and waterways in rural areas. This is because informal workers need regulated access to public space and natural resources to pursue their livelihoods but are routinely dislocated from them. This is also because informal workers, especially in cities, are often seen or portrayed as "undesirable" users of public space: a key source of the structured inequalities they face. There is a need to "unpack" and theorise the social construction of public space and public land in relation to informal livelihoods and, also, informal settlements. In short, the disciplines and practice of urban studies, urban planning and architecture need new or reframed theoretical frameworks to be relevant to all those who live and work in cities.

Despite advances made in statistical measurement of informal employment at the national and international levels, as detailed by Françoise Carré, Rodrigo Negrete and Joann Vanek in their chapters and summarised in the Introduction, more and better statistics are needed. Many countries still do not have a labour force survey, and among those that do, the survey is not done routinely and often does not include questions that provide for the identification of informal employment, both inside and outside informal enterprises. A first priority, therefore, is to encourage countries to undertake labour force surveys on a timely basis with questions on informality harmonised to the International Labour Organization standards. An effort to address this gap among Arab countries is being planned by the ILO, the United Nations Economic and Social Commission for Western Asia (ESCWA) and WIEGO. To facilitate the sustained development of this work, a new regional working group on labour indicators has been organised and will be closely involved with the project. 
Producing "better" statistics involves refining the relevant standards and concepts to reflect changing work arrangements and ensuring that all categories of workers, especially those in the informal economy, are identified in official statistics. WIEGO will participate in a consultation process organised by the ILO concerning the statistical standards of informality. The advice gained from this process will be reviewed by the International Conference of Labour Statisticians (ICLS) in 2023. One concern of the ICLS consultation process is the improvement of statistics on informality to support international harmonisation and coverage across countries, including developed countries. Another concern is refining the concepts related to work in the informal economy to align with decisions taken at the two most recent meetings of the ICLS.

A key issue in aligning the concepts of informality to the new ICLS framework of work relationships involves developing criteria for identifying informality in agriculture, in particular, work in subsistence agriculture. Another key issue is related to changes in the world of work that led to the new classification of status in employment (ICSE-18) described in Chapter 4 by Françoise Carré. This involves the identification of dependent contractors - a category which reflects aspects of both wage and self-employment - and capturing the overlap between informal employment and non-standard forms of wage employment such as short-term work which entails no access to employment-related social protection benefits.

Better statistics also involve the challenge of collecting and tabulating data on the specific occupations of workers in the informal economy, for example, domestic work, home-based work, street vending, market trade and waste picking. These are important sources of employment in developing and emerging economies. However, as described in Chapter 3 by Joann Vanek, these occupations are more difficult to capture in official statistics than those with formal arrangements. Special methods for the collection, classifications and tabulations of data as well as publication in formats that can be used by policy-makers and advocate are required.

A complete picture of a country's informal economy requires not only statistics on employment but also on the contribution of informal enterprises (i.e., the informal sector) and informal workers in formal enterprises and households to the gross domestic project (GDP). A few countries have prepared estimates of the contribution of the informal sector to GDP but only on an ad hoc basis and not as part of the routine statistical production. However, Chapter 5, prepared by Rodrigo Negrete, based on the statistical advances in Mexico, shows the feasibility and importance of the regular production of statistics not only on the contribution of informal enterprises but also on the economic activities of informal workers in formal enterprises or households. Finally, another priority is improved data on informal enterprises: their size, ownership, location and branch of industry and their share of total enterprises and of enterprises in specific branches of industry. 


\section{Future policies}

As summarised in the Introduction, the authors make the case that many existing policies and laws are legacies from the colonial past and are premised on notions of labour markets and employment relations that obtain mainly in the Global North. They also argue that surprisingly little attention has been paid to whether and how existing policies and regulations impact the informal economy, especially in the Global South. Further, while the changing nature of work has captured the attention and imagination of policy-makers, researchers and the general public, there has been limited attention to date on how to regulate new (often informal) forms of work.

The most common policy response to both old and new forms of informal employment is a call to formalise them. But there is limited understanding by policy-makers themselves of what type of formalisation they are calling for: do they want to shift all informal workers to formal jobs, to regulate and tax informal enterprises, to extend social protection to all informal workers or something else? And there is even less understanding of what informal workers want and need in the name of formalisation. Also, in discussing the drivers of informality, more attention is paid to the low capacity of the state than to the deliberate policies of the state - or how the state bends its own formal rules.

What follows is a summary of the dominant narratives about regulation and formalisation of the informal economy and the counter-narratives and recommendations of the authors in this volume, including their deliberations at a 2017 WIEGO research conference held at Harvard University.

\section{Regulation}

In the economics discipline, and among economic policy-makers, there are three persistent and interrelated assumptions about the informal economy and regulation. New research, however, is beginning to challenge these assumptions and provide evidence that further rethinking is necessary.

The first is that excessive regulations - notably labour regulations - drive or cause informality, by creating perverse incentives for firms to operate informally outside the purview of regulations. Elsewhere, Ravi Kanbur has argued that

Even if the presence of regulation could explain the level of informality, for it to explain increases in informality the regulatory burden would have had to have increased. But, in fact, it is well appreciated that in the last two decades of liberalisation, the regulatory burden has, if anything, decreased. The regulation-based explanation of increasing informality is thus weak at best.

(Kanbur 2014: 7)

When it comes to wage employment during this era of de-regulation, many onceformal wage jobs have been informalised because many formal firms are hiring 
workers informally and new forms of work facilitated by digital platforms remain outside the scope of regulation.

The second assumption, a correlate of the first, is that informal workers, businesses and activities operate outside the reach of the law and the state. And the third, a correlate of the second, is that informal workers and operators choose to operate outside the reach of the law and state regulation. In testing these assumptions, as noted in the Introduction, Urmila Chatterjee and Ravi Kanbur found that 97 per cent of manufacturing firms in India have always been smaller in size than the mandated threshold for registration and compliance under the 2011 Factories Act of India and question the policy focus on compliance by informal enterprises (Chatterjee and Kanbur 2015).

Through two decades of research in multiple countries across several continents, the WIEGO Network has found that informal workers, businesses and activities are regulated by the state - typically in ways that are punitive and not well understood. Informal workers and businesses tend to be excluded from labour, employment and business policies and legislation and are, thereby, denied the rights and entitlements afforded to formal employees and businesses. At the same time, a complex range of national, sector-specific and city-level regulations and practices impact informal workers, their businesses and activities. These tend not to fit the reality of informal employment and are frequently punitive in their effect; also, non-compliance with the regulations is often treated as a criminal offence. In India, for example, street vendors who do not have licences, which are difficult to obtain, are subject to summary warrants and fines under the criminal code, despite the fact that middle- and low-income populations rely on them daily to access food and other basic goods and services.

In brief, the informal economy is not outside the reach of the state: rather, informal workers and operators are often inside the punitive arm of the state but outside the protective arm of the state. Elsewhere, Marlese von Broembsen and Marty Chen have reported that state harassment of informal workers and denial of their due process protections under rule of law are ubiquitous around the world. Also, states often fail to implement the relatively few progressive laws that are designed to protect or support informal workers (von Broembsen and Chen 2016). What informal workers need in order to increase their income and thereby contribute to economic growth and the reduction of poverty and inequality are enabling and protective laws and regulations and the benefits that come with registering their enterprises and paying taxes. The policy challenge is to identify which forms of regulations affect which segments of the informal economy in what ways; and to develop appropriate and fair regulations for different segments - in consultation with and informed by the perspectives of informal workers.

In terms of specific recommendations by the authors, the economists point out that many informal workers fall outside, rather than avoid, existing regulatory frameworks and tax thresholds. They also argue that policies should focus on raising the productivity of informal businesses and the incomes of informal workers. The labour lawyers and scholars argue that labour and employment 


\section{Martha Chen et al.}

laws, premised on an explicit employer-employee relationship, need to be reframed to cover informal employment relationships. The urban planners and scholars argue that informal livelihoods and informal settlements, and the links between then, need to be integrated into urban plan and designs. The social policy scholars call for an integrated approach to social protection for informal workers that includes both social assistance and social security, that sees a role for both the state and employers in providing social protection, and that extends protection to informal workers as both workers and citizens. The sociologists and political scientists challenge assumptions about the relationship between the state, capital, labour and informality and argue that more policy attention should be paid to the informal practices of the state and capital. The home-based worker, street vendor and waste picker specialists argue that existing policy and legal frameworks should be reframed to match the realities and needs of these and other groups of informal workers, rather than requiring informal workers to comply with inappropriate laws designed for formal employment and commercial arrangements.

\section{Formalisation}

At the heart of the policy debates on the informal economy is the question of whether and how to formalise the informal economy. Different analysts and stakeholders hold divergent notions of what formalisation of the informal economy should entail. To some, it means shifting informal workers to formal wage jobs - but this requires creating more formal wage jobs. To others, it means registering and taxing informal enterprises. But, as noted by Ravi Kanbur as well as Imraan Valodia and David Francis, many informal operators already pay a variety of taxes and fees. Further, as noted by Sonia Dias, Lucía Fernandez, Sally Roever and Melanie Samson writing about street vendors and waste pickers, informal workers want the benefits that should come with being formalised in exchange for paying taxes.

WIEGO has sought to influence the formalisation debate to reflect the priority needs and demands of informal workers, based on its grounded knowledge of, and engagement with, different groups of informal workers. WIEGO has pointed out that formalisation policies have different meanings and implications across different groups of informal workers; and that the formalisation debate tends to focus narrowly on the self-employed in informal enterprises and, especially, on the more entrepreneurial self-employed, namely, employers who represent around 3 per cent of informal self-employed globally (ILO 2018a). At a minimum, the formalisation debate needs to distinguish between wage workers in informal jobs and self-employed workers in informal enterprises. Ideally, it should further distinguish between different segments of the informal selfemployed and wage employed as each segment has its specific needs and constraints (Chen 2006, 2009).

WIEGO facilitated a delegation of informal worker leaders to the two-year standard-setting discussion on the "Transitioning from the Informal to the 
Formal Economy" at the International Labour Conferences in 2014 and 2015. To prepare the delegation for these discussions, including the formulation of a common platform of demands, WIEGO convened three regional workshops with informal worker leaders from 55 organisations and 24 countries. The common core demands of the informal worker organisations include: the right to organisation, collective representative voice, legal identity and standing as well as labour rights, economic rights and social rights, including social protection. The WIEGO Network Platform also includes the demands of specific groups of workers (WIEGO Network Platform 2014).

ILO Recommendation 204 on the "Transitioning from the Informal to the Formal Economy", adopted at the 2015 International Labour Conference, includes some of the key demands of the informal worker delegation, notably the recognition that: most informal workers are from poor households trying to earn a living against great odds who need protection and promotion in return for regulation and taxation; most informal economic units are single person or family operations run by own-account workers who do not hire others; regulated access to public space and natural resources are essential to the livelihoods of informal workers; and informal livelihoods should not be destroyed in the process of formalisation. But the Recommendation falls short in granting the membership-based organisations of informal workers a guaranteed and direct seat at the ILO tripartite standard-setting negotiation table, due in large part to resistance from some trade unions of formal workers.

Since Recommendation 204 was adopted in 2015, there has been increasing pressure on governments to formalise the informal economy. Several authors in this volume, notably Barbara Harriss-White, Amin Kamete, Kate Meagher, Melanie Samson and Kamala Sankaran, have written about adverse terms of formalisation, questioning whose agenda is being served. Amin Kamete makes the case that some approaches to formalisation are coercive and force the informal workers into "making crippling Faustian bargains that strip away the very soul of informality". As a case in point, the recent demonetisation scheme and the new Goods and Services Tax (GST) in India - both promoted in the name of formalising the informal economy - have served to cripple, rather than formalise, informal enterprises and workers. Demonetisation disproportionately affected the (predominantly informal) firms that deal in cash. GST compliance has forced business transactions to be digitalised, and compelled formal firms to prefer formal suppliers and informal firms to deal with more complicated bureaucratic procedures and the loss of contracts from formal firms. In the process, the number of jobs in informal enterprises has declined (Kumar 2019). As a sector-specific example of formalisation, Melanie Samson presents a typology of approaches to integrating waste pickers in solid waste management and the associated "erasures" of the identity, knowledge and systems of waste pickers.

It is also important to note, as James Heintz highlights in Chapter 8, that the formalisation debate "tends to be flawed because it considers the path to formality to be an incremental one, based on individual enterprises or jobs" and the 
transition from informality to formality to be a simple continuum. He notes that many research projects try to document how informal enterprises can move up from very micro, to micro, to small, then medium-scale enterprises. James Heintz questions whether this can or should happen one firm at a time; argues that the ability of one firm to formalise may depend on what is happening to other enterprises in the economy, that is, to the economy's structure as a whole; and calls for more research in this area to truly understand the dynamics of informal employment and formalisation.

Finally, the authors of this volume raise fundamental issues about the politics of formalisation. They question "who should comply with what?" in the name of formalisation. Must informal workers comply with existing formal policies and regulations that are not designed for them? Or do formal policies and regulations need to be amended to match the realities and needs of informal workers? Or do the state and capital need to comply with the formal policies and regulations which they often avoid or find exceptions to? In other words, the authors question whether the end goal is to formalise informal workers, their enterprises and livelihood activities by making them comply with existing policies and laws. Instead, they argue that the end goal should be to reform existing policies and laws to match the realities and needs of informal workers. In making the case that municipal and industry recycling systems should integrate into the recycling system of informal waste pickers, Melanie Samson cites a South African waste picker who told a group of national and local officials: "It is the city who is integrating itself on our existing structures, because we've been doing it for many years, so it is them who is integrating onto our existing system."

But what about the difficult political challenge of who should - and can regulate the state and capital, especially when they collude to bend formal rules? Consider the case of global value chains, a mode of global production which encourages governments to attract foreign investors by relaxing regulations and multinational companies to shift production to countries with the least-onerous regulations or weakest enforcement. To regulate homework in global value chains, Marlese von Broembsen recommends a "plural-overlapping conception of governance" which combines national regulations with "different forms of governance at different jurisdictional spheres". Von Broembsen sees a role for organisations of homeworkers in the governance of global value chains but cautions that the burden of regulation and enforcement should not fall solely on homeworkers and their organisations: and calls for multi-stakeholder governance involving trade unions, citizen groups, corporations and the state as well as homeworker organisations. Similarly, Adele Blackett makes the case for transnational regulation of domestic work, an occupation associated with significant cross-border migration.

To sum up, the authors make the case that, in the discourse on regulation and formalisation, there is too much focus on the non-compliance or deviance of informal workers and too little focus on the non-compliance and deviance of state and capital and on the inappropriateness of existing policy and legal frameworks. They also point out that there is limited focus on institutions and power 
and how, more specifically, the state and capital not only bend formal rules in their favour but also use formal rules to penalise informal workers.

\section{Future vision}

\section{Vision}

What is being suggested by the authors is a fundamentally different approach to the informal economy within their specific disciplines - and more generally. An approach that is centred on informal workers, especially the working poor: their needs, constraints and aspirations as well as their contributions to the economy, society and environment. In other words, an approach in which informal workers themselves - as well as their needs and demands - matter in research and policy. This approach needs to be led by realities and perspectives in the Global South, to be bottom-up and incremental, and to embrace the fluidity and flexibility of informality while addressing the associated vulnerabilities for informal workers.

In practical terms, this approach should seek to reduce the vulnerabilities and increase the earnings - and productivity - of informal workers. Doing so requires an approach that focuses on linkages between informal settlements and informal livelihoods, on the adherence of formal regulations to informal realities, and on the compliance of state and capital with formal regulations, rather than just the compliance of informal workers and enterprises with existing formal regulations. The approach would combine economic analysis with analysis of power dynamics in specific contexts - and, ideally, historically - and bridge calls for efficiency with calls for social justice.

As a group, the authors question whose visions and interests are being served in the name of regulating and formalising the informal economy: the visions - or dreams - of informal workers or the visions of the state (which is often ensnared by powerful interests), of capital, of economic and urban planners. In sum, the authors challenge attempts to integrate informal workers into existing legal and policy frameworks and existing models of labour markets - because the existing frameworks and models are not designed for them and, therefore, are either inappropriate for, biased against, or punitive towards them.

\section{From vision to reality}

Turning this fundamentally different vision into reality will require addressing the politics of competing interests and power imbalances. It will require addressing the fact that states are often "divided" between the expectation that they should serve as guarantor of rights and the rule of law and the temptation or incentives they face to violate the rights of the less powerful and their own laws. It will also require addressing the fact that the national or local state often colludes with capital or is subordinated to, or overpowered by, capital. It will also require addressing the fundamental imbalance of power between informal workers, especially the working poor, and the state and the owners of capital. 
To address these realities, the authors call for a new cohort of economic and urban planners who, as Caroline Skinner and Vanessa Watson put it, "are willing (and brave enough) to try out new approaches" as a few activist academics, together with organisations of informal workers, have already done in the cases highlighted in this volume. More fundamentally, the authors recognise that those who work and live informally have the best, most nuanced understanding, of their own context and have begun to challenge the very notion of "who is a planner" and "whose interests are being served in plans".

\section{Future governance}

What is needed going forward, as Melanie Samson puts it, is to challenge the existing policy-making processes, captured by the rich and powerful, and to privilege the knowledge and collective voice of informal workers in the policy process. This will require genuinely inclusive rule-setting and planning processes as well as negotiation and conflict resolution processes to reconcile the competing vision and interests of informal workers and other, more powerful, stakeholders.

The authors also argue that inclusive policy and negotiating processes should not only include organisations of informal workers but be led by them. This is both feasible as well as desirable, as illustrated by the promising examples of policy processes and outcomes led by organisations of informal workers that are featured in this volume: including municipal contracts for waste pickers in two cities in India and over 25 cities in Colombia; recognition of the natural markets of street vendors in a new law on street vending in India; new supportive legislation for homeworkers and domestic workers in Thailand; and new labour legislation in Ghana that covers all workers, formal and informal. These substantial gains offer models to counteract common views that informal workers are unorganisable, divided, and insignificant economic actors unworthy of constructive policy intervention.

One final important point. In the early twentieth century, when all workers were informal, they began to demand - and to design - the rights and benefits of what is now considered "standard" formal wage employment. In the early twenty-first century, informal workers are also making demands - but their demands are different because labour markets and economies today are different than those 100 years ago. Despite the formal labour standards negotiated in the early twentieth century, today over half of all workers globally are informally employed, nearly half are self-employed (mostly own-account or contributing family workers) and new forms of non-standard or informal work are emerging. Informal workers today are demanding recognition, protection and support as informal workers, both wage-employed and self-employed. In sum, informal employment, not formal employment, dominates global employment today and is likely to continue to do so. What is needed, and recommended by the authors, is to transform formal policies, regulations and institutions to reflect the reality and perspectives of informal workers, their knowledge and their understanding of the wider environment and their way of working within it. 